\title{
Sandy Green As I Knew Him
}

Personal impressions to memorialize Professor J. A. Green as a teacher and a friend

\author{
Ahmed A. Khammash
}

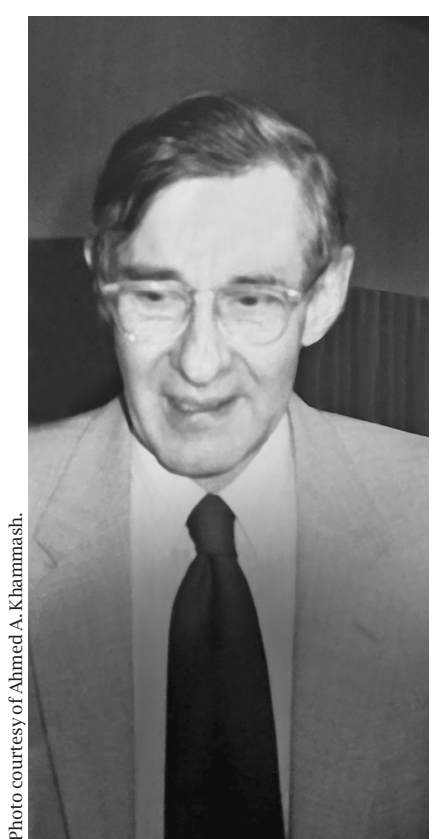

Sandy was a sociable person with a very humble, simple, and inspiring character.
Professor J. A. Green (or Sandy Green, as people used to call him) passed away on April 7, 2014. This short note is a personal impression to memorialize Sandy as a teacher and a friend, recorded from my experience at Warwick University as a graduate student under his supervision, as well as from notes and letters which I treasure with great honor. Sandy's outstanding achievements were summarized in his London Mathematical Society De Morgan Medal citation [PC]: "It is internationally agreed that Green is one of those who have most shaped modern representation theory, and he enjoys widespread respect and affection.” And from Karin Erdman's consolation message [KE]:

He has made a huge impact on representation theory. Highlights include the characters of general linear groups over finite fields, the "Green correspondence", the Green functions. His monograph on polynomial representations of $G L_{n}$ (where he introduces Schur algebras) has become very influential and the basis of a lot of recent research. He was strongly involved in the development of

\footnotetext{
Ahmed A. Khammash is professor of mathematics at Umm Al-Qura University, Mecca, Saudi Arabia. His email address is aakhammash@ uqu. edu. sa.

For permission to reprint this article, please contact: reprint-permission@ams .org.
}

DOI: http://dx.doi.org/10.1090/noti1392 the classical Hall algebra theory. Many will have seen his theorem on Hall algebras, which describes for a quiver the positive part of the corresponding quantum group.

When I arrived at the University of Warwick in the autumn of 1982 to pursue my graduate studies in algebra, Christopher Zeeman, chairman of the mathematical institute, told me, while he was making his afternoon cup of tea at the department kitchen, that the department had appointed Green as my supervisor. At that time, despite Sandy's worldwide scientific reputation, the only information that I knew about him was what was written on the board of the institute staff: his name, his photo, and the directions to his office. The next day he greeted me warmly and took a small diary book out of his pocket in order to fix the time of our weekly meetings. Then he handed me Sutherland's Introduction to Metric and Topological Spaces and pointed at an exercise at the end. I realized only afterwards that topology is an essential tool in modular representation theory.

Sandy was very organized in teaching and lecturing. Although he came to class with beautifully hand-written lecture notes, he never consulted them. He was fond of concrete examples. When he would teach a deep and constructive subject such as Auslander-Reiten theory, cohomology of groups, modular representations or invariant theory he would not give general theories or construction algorithms without giving concrete detailed examples; he liked to give examples of

$$
\begin{aligned}
& \text { "It is very } \\
& \text { dangerous } \\
& \text { to refuse." }
\end{aligned}
$$
how to construct almost split Auslander-Reiten sequences and A-R quivers for certain finite-dimensional algebras. The interactive class was one of his favorite methods; he would mandate each student in the class to teach one lecture. When he asked me early in my first semester to give a lecture, I demurred. He responded, "It is very dangerous to refuse." 


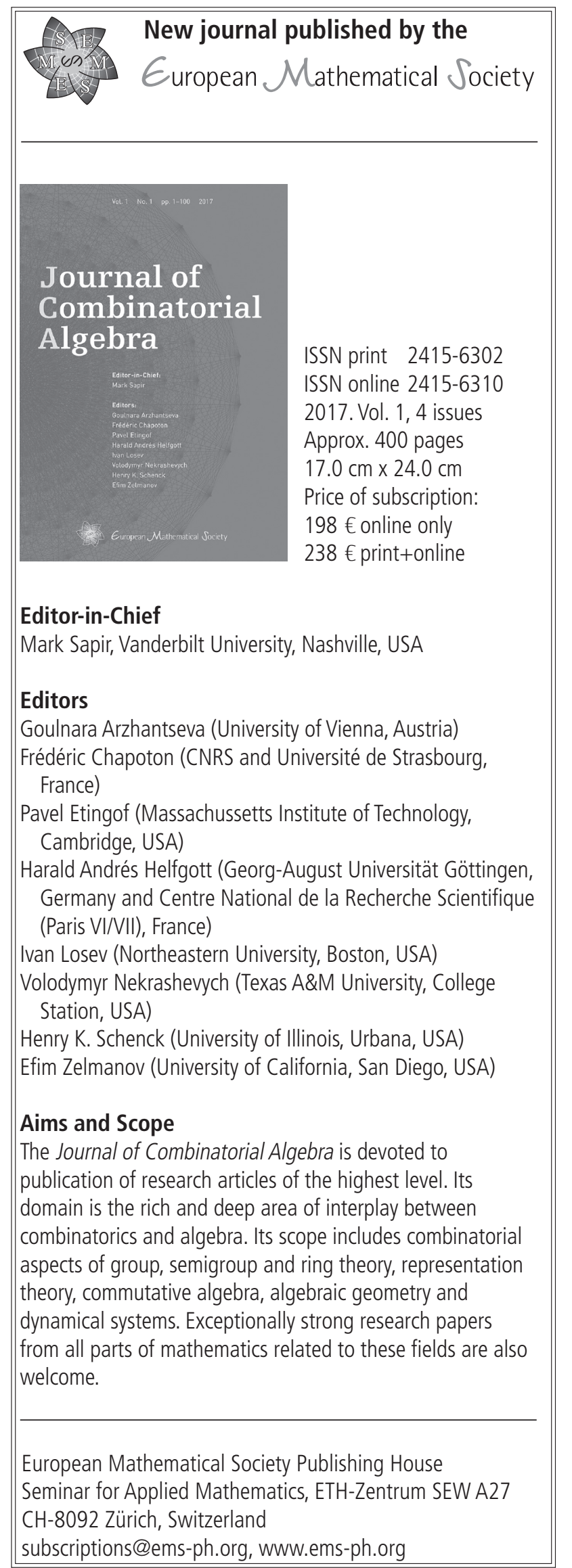

Sandy liked details, coherence, rigorous proofs, and examples enhanced with explanatory figures and diagrams. Below is Sandy's careful illustrative examples of the Lyndon-Hochschild-Serre spectral sequence.

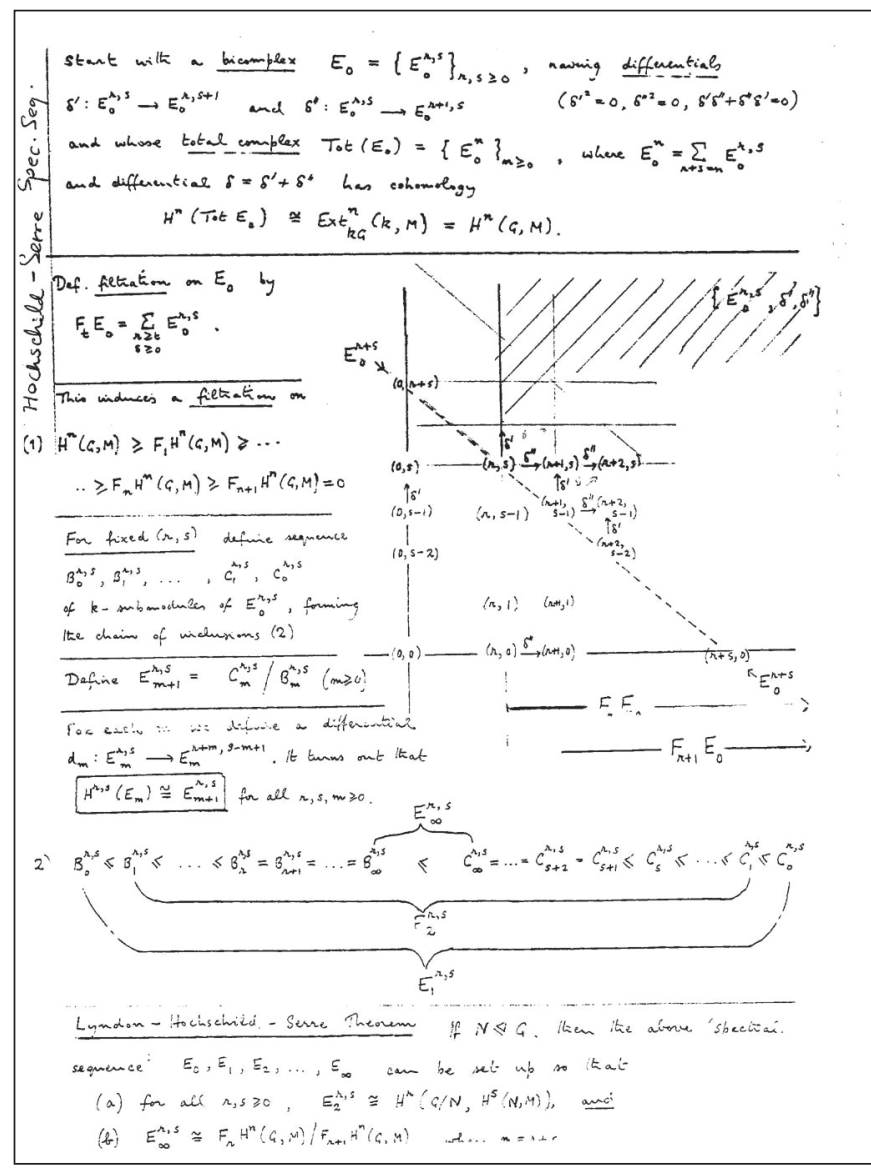

Sandy was a sociable person with a very humble, simple, and inspiring character. He spoke in a very relaxing and convenient way so that you would not get tired of talking to him. M. Collin wrote [MC]:

Above all, Green should be described as a "gentle man." His voice was never raised; logic and clarity sufficed. His lectures were a model of elegance and precision, with a delivery reminiscent of Brauer's. But while he was a mathematician first, he was never aggressively so, and maintained a balance of interests, whether French literature, gardening or his family, and he brought the same degree of interest and care to all those whom he met professionally, whether faculty or students.

\section{References}

[MC] Michael Collins and SANDY GReEN, Mathematician who worked at Bletchley before becoming a leading figure in the discipline of representation theory, The Independent 20 (July, 2014).

[KE] KARIN ERDMANN, A message of consolation, FDList, fd1ist@ math.uni-bielefeld.de, on April 8, 2014.

[PC] Prizewinners: Citation for James Alexander Green, Bull. London Math. Soc. 34 (5) (2002), 633-640; nnews 1etter . 1ms . ac . uk/jamesalexander-sandy-green-1926-2014/. 